\title{
Pesquisa de Listeria monocytogenes em Queijos Fatiados Comercializados em Estabelecimentos Varejistas Na Cidade de Goiânia
}

Ana Clara Melo Lima (I), Luiza Chaul Toubas (I), leda Maria Sapateiro Torres (I), Telma Alves Garcia (I), Virgínia Farias Alves (I)

(I) FF-UFG - Faculdade de Farmácia -UFG (Goiânia, GO, Brasil)

\section{Resumo}

Listeria monocytogenes é o agente causal da listeriose, uma doença de caráter oportunista e grave, que afeta especialmente alguns grupos populacionais como gestantes, neonatos, idosos e imunodeprimidos. Os alimentos são reconhecidos como os principais veículos de transmissão da bactéria, sendo considerados de alto risco especialmente os prontos para consumo (APC), que apresentam longa vida de prateleira sob refrigeração e são consumidos sem aquecimento prévio. Diferentes tipos de derivados lácteos, especialmente queijos, já foram incriminados tanto em casos esporádicos quanto em surtos de duração variada da doença. Dessa forma, o objetivo do presente trabalho foi verificar a presença de $\mathrm{L}$.

monocytogenes em amostras de queijo muçarela fatiado, comercializadas em estabelecimentos varejistas da cidade de Goiânia, GO. Para tanto, entre os meses de fevereiro e maio de 2014, um total de 16 amostras do produto foram adquiridas em padarias e supermercados locais e encaminhadas para análise no Laboratório de Pesquisa em controle de Qualidade de Alimentos e Medicamentos da Faculdade de Farmácia da Universidade Federal de Goiás. As análises foram conduzidas de acordo com o protocolo preconizado pelo Food and Drug Administration, utilizando-se dois meios de enriquecimento (BLEB e caldo Fraser) e plaqueamento em superfície de ágar Oxford e ágar Palcam. Até 5 isolados suspeitos para o gênero Listeria foram submetidos aos testes de coloração de Gram, catalase, motilidade a $250 \mathrm{C}$ e fermentação de carboidratos. A confirmação dos resultados foi feita 
utilizando-se o kit Api Listeria. A presença de L. monocytogenes foi confirmada em três $(18,75 \%)$ das 16 amostras de queijo muçarela avaliadas. Não foram encontradas outras espécies do gênero Listeria nos produtos avaliados. Apesar de, no Brasil, ainda não ter sido possível estabelecer a relação entre alimentos e doença, os resultados do presente estudo evidenciam que o queijo muçarela fatiado pode atuar como importante veículo para transmissão da bactéria, constituindo, dessa forma, risco para os consumidores.

Palavras-Chave: Alimentos Prontos para Consumo, Listeria monocytogenes, Queijo Muçarela Fatiado

Agência de Fomento: FAPEG 